\title{
How Stakeholder Assessment of E-Prescribing Can Help Determine Incentives to Facilitate Management of Care: A Delphi Study
}

\author{
Paul R. DeMuro, PhD, JD, MBA; Joan Ash, PhD, MLS, MBA; Blackford Middleton, MD, MPH, MSc; \\ Justin Fletcher, MBI, PhD; and Cecelia J. Madison, MBI
}

\begin{abstract}
BACKGROUND: Little research has been conducted on the quality, benefits, costs, and financial considerations associated with health information technology (HIT), particularly informatics technologies such as e-prescribing, from the perspective of all of its stakeholders.

OBJECTIVES: To (a) identify the stakeholders involved in e-prescribing and (b) identify and rank order the positives and negatives of e-prescribing from the perspective of stakeholders in order to create a framework for payers, integrated delivery systems, policymakers and legislators, and those who influence public policy to assist them in the development of incentives and payment mechanisms that result in the better management of care.
\end{abstract}

METHODS: The Delphi method was used to enlist a panel of experts in e-prescribing, informatics, and/or HIT who have published in the field. This panel was presented with the results of initial research and an online survey of questions that sought to prioritize the quality, benefit, cost, and financial effects of e-prescribing from the perspective of each stakeholder. Eleven experts completed the first survey, which contained a list of stakeholders and positives and negatives associated with e-prescribing. Nine of the 11 experts completed the second survey, and 7 experts completed the final survey. From the results of these 3 surveys, a framework was presented to 5 framework experts, who were representatives from payers, integrated delivery systems, policymakers and legislators, and those who influence public policy. These framework experts were interviewed regarding the usefulness of the framework from their perspectives.

RESULTS: The experts added stakeholders and many positives and negatives to the initial list and rank ordered the positives and negatives of e-prescribing from the perspective of each stakeholder. The aggregate results were summarized by stakeholder category. The positives and negatives were categorized as health, finance, effort, time, management, or data concerns. The framework experts evaluated the framework and found it useful.

CONCLUSIONS: Positives and negatives associated with e-prescribing in the areas of quality, benefits, costs, and financial considerations can be rank ordered from the perspective of each stakeholder. The experts agreed on some points but disagreed on others. For example, they agreed that the main negative of e-prescribing from the perspective of pharmacists and pharmacies was its implementation costs but differed on the importance of providing faster information transfer. A framework was created that could be successfully used by payers, integrated delivery systems, policymakers and legislators, and those who influence public policy for the development of incentives and payment mechanisms.

J Manag Care Spec Pharm. 2017;23(11):1130-39

Copyright $\odot 2017$, Academy of Managed Care Pharmacy. All rights reserved.

\section{What is already known about this subject}

Payers, integrated delivery systems, legislatures, and those who influence public policy have struggled to understand the quality, benefits, costs, and financial considerations associated with health information technologies, such as e-prescribing.

E-prescribing has the ability to improve the quality of care while reducing the cost of health care, but there is limited research on the quality, costs, and return on investment.

\section{What this study adds}

All the stakeholders involved in e-prescribing are identified. The positives and negatives from the perspective of each stakeholder are identified and rank ordered.

The framework developed was shared with experts who analyzed it for its usefulness to payers, integrated delivery systems, policymakers and legislators, and those who influence public policy.

$\mathrm{H}$ ealth informatics applications, such as e-prescribing, have the capability to improve the quality of care while reducing the cost of health care, ${ }^{1}$ improve prescriber and pharmacy productivity and work flow, ${ }^{2}$ and result in lower prescription medication costs. ${ }^{3}$ However, much of the research to date does not identify all stakeholders and all benefits, including quality and cost considerations and whether benefits are direct or indirect, tangible or intangible, or financial or otherwise..$^{1,4-7}$ There is research on formulary compliance, pharmacy technology assessment, quality, costs, and return on investment (ROI), ${ }^{8,9}$ but much of this research appears to be limited to the costs and benefits associated with the implementation of informatics technologies such as an electronic health record (EHR) systems in a particular setting (e.g., a medical group or hospital setting). ${ }^{10-12}$

Several studies have focused on personal health records (PHRs), with cost models and frameworks for assessing the value of PHRs. ${ }^{13,14}$ Byrne et al. (2010) studied EHRs, estimating the value of having the integrated components of the VistA EHR compared with not having the components of similar health information technology (HIT). ${ }^{15}$ Cusak et al. (2008) assessed the ROI of telehealth systems using a sensitivity analysis, ${ }^{16}$ while Kaushal et al (2006) looked at the ROI for a computerized provider order entry system in a hospital. ${ }^{17}$ 
Additional studies have considered the cost of interconnecting health information exchanges (HIEs) to form a national network, the value of health care information exchange and interoperability, and the economic benefits of HIE interoperability for Australia. ${ }^{18-20}$ These studies contribute to the body of knowledge in this area but, by their nature, consider varying definitions of quality, benefit, and costs. Together, they provide no general consensus regarding structure and costs of informatics technologies, such as those that might be used by a national health information network. ${ }^{21}$ In addition, stakeholders, such as policymakers, often have to rely on estimates that are based on expert opinion. ${ }^{22}$

A true e-prescribing system is a closed-loop system in which the entire process of prescribing a medication is electronic from beginning to end: A clinician prescribes medications; prescriptions are sent electronically to a pharmacy; and feedback returns to the clinician when patients collect their prescriptions. ${ }^{23}$

Given the state of the research and the limited nature of the models that have been developed, some potential purchasers might conclude that the benefits of e-prescribing do not outweigh its costs and that the ROI associated with such informatics technologies is insufficient to warrant implementation. However, advances in HIT are creating new opportunities for pharmacists to assist in the improvement of the efficiency and quality of health care. ${ }^{24}$

Payers, integrated delivery systems, legislatures, and those who influence public policy have struggled to understand the quality, benefits, costs, and financial considerations associated with HIT, particularly informatics technologies. This lack of understanding is particularly apparent with respect to decision making regarding the development and implementation of incentives and payment mechanisms to facilitate the transformation from fee-for-service payments to payments for quality and cost-effectiveness. Individuals and entities designing payment systems and incentives do not have all the information they need because not all stakeholders affected by such payment arrangements have been identified, and the relative importance of stakeholder considerations is unknown. Further, there is a misalignment of incentives in current health care systems.

The increase in new integrated approaches to the delivery of care, such as accountable care organizations and patient-centered medical homes, likely will create new roles and responsibilities for pharmacists. ${ }^{24}$ The nature and extent of such roles and responsibilities will be determined in the context of the applicable stakeholders and the positives and negatives from their perspectives of HIT. Consequently, pharmacists should play key roles on care teams that will be facilitated by HIT. ${ }^{24}$
With our research, we sought to fill the gap that exists in the current research by using e-prescribing as an example of HIT for which all the stakeholders and the applicable quality, benefit, cost, and financial considerations are identified and prioritized. HIT systems differ in their functionalities, just as EHRs have different features and functions. ${ }^{25}$

The objectives of this study were to (a) identify the stakeholders involved in e-prescribing and the attributes from the perspective of each stakeholder and (b) rank order items to assess which attributes had the greatest effect on the positive and negative aspects for each stakeholder. To accomplish these objectives, 3 specific tasks were undertaken:

1. Develop a process to identify the most important quality, benefit, cost, and financial effects and prioritize them for stakeholders.

2. Provide in chart form what was learned about quality, benefit, cost, and financial effects.

3. Determine whether the findings are useful for payers, integrated delivery systems, policymakers and legislators, and those who influence public policy in making decisions about motivating stakeholders to use e-prescribing through aligned incentives in payment for quality and cost-effectiveness.

\section{Methods}

\section{The Delphi Method}

For this study, the Delphi method was used, which is a structured communication technique intended to obtain the most reliable consensus of a group of experts. ${ }^{25-29}$ Anonymous experts can address a complex problem through feedback on individual contributions of information and knowledge. A series of questionnaires in 2 or more rounds is used, which does not allow for direct confrontation of the experts. In a Delphi study, the expertise of the experts is more important than the number of respondents. Wang et al.'s 2003 costbenefit analysis of EHR usage by primary care physicians in an ambulatory care setting provides an example of the use of the Delphi method in a health care setting. ${ }^{10}$ In this study, the experts completed 3 rounds of questionnaires: a brainstorming round (round 1), a narrowing round (round 2), and a finalizing round (round 3).

\section{Literature Search for Experts and Stakeholders}

A comprehensive literature search of the use of HIT, particularly informatics technologies and their ability to assist in providing quality care in a cost-effective manner, yielded more than 200 researchers, stakeholders, noted authorities, and others who might be able to serve as experts for this study. A subset of 31 researchers were identified by reviewing their substantive contributions to their fields, the nature of their institutions, their many relevant publications, and their reputations as experts in their fields as known by certain of the study authors. These researchers were invited by email to participate 
in this study. All the experts who participated had doctoral or terminal degrees, were from leading institutions and entities, and were recognized authorities in their fields. They were from 5 countries that use e-prescribing systems (Austria, Sweden, Italy, the United Kingdom, and the United States) and 6 geographically diverse states in the United States (Massachusetts, New York, Ohio, Oregon, Pennsylvania, and Texas).

A search of published literature yielded a list of stakeholders and potential positive and negative aspects related to the use of HIT. Primary stakeholders were defined as those directly involved in the e-prescribing process. Secondary stakeholders were defined as those indirectly involved in the e-prescribing process. All stakeholders were categorized according to whether they were primarily involved in the business of e-prescriptions, paying for e-prescriptions, receiving e-prescriptions, involved with providing e-prescriptions, regulating e-prescriptions, or studying e-prescriptions.

A comprehensive literature and Internet search was used to identify existing models and the positive and negative aspects for each stakeholder. Search terms included e-prescribing, electronic health records, health information technology, quality, benefits, costs, cost-benefit analysis, and return on investment.

\section{Surveying the Experts}

The experts were presented with the results of the initial research and questions in an online structured survey questionnaire via SurveyMonkey (Palo Alto, CA), which facilitated identification of additional stakeholders and prioritization of positive and negative aspects of HIT, particularly informatics technologies such as e-prescribing. The experts were asked to prioritize positives and negatives from the perspective of individual stakeholders. The electronic questionnaire was designed to automatically aggregate the data and compile the rank order based on the weighted averages of the expert responses.

Thirteen experts, 9 from within the United States and 4 based outside the United States, participated in round 1, an adequate response rate for a Delphi study. This first questionnaire presented the list of stakeholders affected by e-prescribing and a list of the positives and negatives of e-prescribing for each stakeholder. After reviewing the list, the experts had the opportunity to add other stakeholders. When new stakeholders were chosen, the experts were asked to describe positives and negatives of e-prescribing from the perspective of these stakeholders. The order in which the positives and negatives were presented was randomized for each participant in the first round by the survey software. The experts were given the opportunity to add other positives and negatives. They were asked to rank order the items on each list. The experts were not advised of the identity of the other respondents, as is customary in studies based on the Delphi approach.

In round 2, the same group of experts were presented with and completed a narrowing questionnaire where the positives and negatives were in the order determined by round 1 . In this second round, the experts were asked to redo the rank order of the e-prescribing positives and negatives from the perspective of the original stakeholders and to comment on additional positives and negatives for the new stakeholders. Nine experts completed this second round.

In round 3, the positives and negatives and the rank order from the perspective of each original stakeholder that were determined in round 2 were presented to the experts from round 2 and 1 expert from round 1 who did not participate in round 2. They were asked to perform a final rank ordering and were provided with the opportunity to comment on any significant aspects of the relative effect of e-prescribing and on any aspect of e-prescribing's positive or negative effects on any of the stakeholders. Seven experts completed the third round. All survey instruments were completed between October 18, 2014, and February 28, 2015.

\section{Chart Preparation}

Charts were prepared for each identified stakeholder noting the positives and negatives associated with e-prescribing. The positives and negatives were rank ordered, computed as weighted averages, and converted to proportions (calculated as the attributes weighted average divided by the number of attributes), except for the positives and negatives that were identified for the new stakeholders. The numbers associated with each attribute are the proportional value assigned by the Delphi experts to the attribute, with 1.0 meaning that all respondents ranked it first and 0.0 meaning that all respondents noted it as not applicable. For example, on a survey question with 4 attributes, an attribute with a weighted average of 3 after the final rank ordering by the experts would be assigned a proportional value of 0.75 .

In addition to providing the proportional values of the attributes, and to support the framework's objectives of providing succinct and easily assimilated information, we categorized the positives and negatives as health, including safety and wellbeing of people; finances (revenue and expenses); effort (the nature and extent of which people must apply to an endeavor); time (required by an endeavor); management (the nature and extent of the tasks of an endeavor); and data (the quantity, quality, and/or security of the data used by an endeavor). Charts representing key stakeholders appear as Tables 1-5.

\section{E-Prescribing Framework}

Five framework experts were identified from a list of payers, integrated delivery systems, policymakers and legislators, and those who influence public policy. Four experts were from the United States, and 1 expert was from the United Kingdom (see Appendix A, available in online article, for descriptions).

The charts prepared for each stakeholder formed the e-prescribing framework that was presented to the framework experts, who reviewed it for its usefulness in assisting payers, 


\begin{tabular}{|l|}
\hline TABLE 1 \\
\hline \\
\\
\hline Health \\
Finances \\
Effort \\
Time \\
Management \\
Data
\end{tabular}

Key Stakeholders: Patients-E-Prescribing Positives and Negatives ${ }^{\mathrm{a}, \mathrm{b}}$

Positives

Fewer medication errors 0.95

Fewer adverse drug events 0.89

Improved patient safety 0.85

Convenience 0.81

Fewer errors in prescriptions 0.77

Increased efficiency 0.74

Lower-cost options 0.65
0.86 Need to find a pharmacy/dispenser that uses e-prescribing

0.82 Controlled substances may have to be separately purchased

0.79 Need to find a provider that uses e-prescribing

0.70 Pharmacy must be chosen when prescription is made

0.63 Loss of immediate physical trail of prescription

0.61 Less likely to get nonformulary medications

Available patient medication history 0.59

Improved care and/or health outcomes 0.56

Better medication adherence/compliance 0.49

Improved communication 0.45

Faster information transfer 0.45

Easier to report adverse drug events 0.40 Increased or improved decision support 0.38

Increased awareness of and perceived control over active medications 0.26

Improved adherence to guidelines 0.21

Easier to get reimbursed for medications 0.19

Improved governmental oversight of controlled substances 0.18

Improved health care management 0.16
0.56 Privacy concerns due to risk of violation of data security

0.46 Time consuming for providers

0.36 Potential for new major errors, creating adverse effects on safety

0.27 Potential for new minor errors, creating inconvenience

0.25 Entirely dependent on technology

0.05 Harder to acquire fraudulent prescriptions to sell on the black market

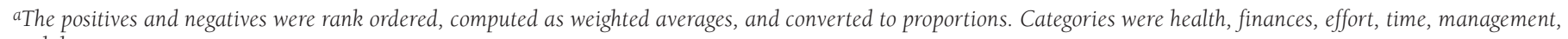
and data.

${ }^{b}$ The positives and negatives that were added by the respondents in round 1 are shown in italics.

integrated delivery systems, policymakers and legislators, and those who influence public policy in developing incentives and payment mechanisms. The usefulness of the framework lay in its representation of who and what entities might be affected by e-prescribing.

The e-prescribing framework was emailed to the 5 framework experts on March 24, 2015, with a request to schedule an interview to discuss the questions posed, which concerned the usefulness of the framework. The framework experts were then interviewed via telephone or Skype, using the provided questions (Appendix A). One of the study authors took notes from those interviews and recorded summaries of the interviews. Interviews were conducted between April 6 and April 16, 2015.

\section{Results}

\section{Key Primary Stakeholders}

The key primary stakeholders in e-prescribing were identified as patients, clinicians and prescribers, pharmacy benefit managers and prescription pricing authorities, payers and purchasers, and pharmacies, dispensers, and pharmacists. From the survey rounds, the main positives and negatives of e-prescribing for each key stakeholder are summarized as follows:

Patients. Positives: fewer medication errors, fewer adverse drug events, improved patient safety, and convenience. Negatives: the need to find a pharmacy/dispenser that used e-prescribing, the possible need for controlled substances to be dispensed separately, and the need to find a provider that used e-prescribing. The respondents mentioned 9 other negatives (Table 1).

Clinicians and prescribers. Positives: available patient medication history and time savings. Negatives: poor fit with workflow, implementation costs, training, software licensing fees, and the possible need for controlled substances to be prescribed separately (Table 2).

Pharmacy benefits managers and prescription pricing authorities. Positives: reduced costs and increased generic/formulary 


\section{TABLE 2 Key Stakeholders: Clinicians and Prescribers-E-Prescribing Positives and Negatives ${ }^{\mathrm{a}, \mathrm{b}}$}

\begin{tabular}{l}
\hline . \\
\hline \\
Health \\
Finances \\
Effort \\
Time \\
Management \\
Data
\end{tabular}

Increased efficiency 0.62

Better ability to monitor adherence/compliance 0.55

Improved communication 0.46

Increased or improved decision support 0.44

Fewer documents 0.39

Faster information transfer 0.30

Iimproved care and/or health outcomes 0.27

Improved patient satisfaction 0.25

Lesser professional liability premiums and malpractice liability 0.10

\section{Negatives}

0.98 Poor fit with workflow

0.95 Implementation costs

0.89 Training

0.86 Software licensing fees

0.85 Controlled substances may have to be separately prescribed

0.79 Health care coverage and/or formulary may not be updated

0.75 Menu designs may increase wrong drug choices

0.74 Time consuming

0.72 Maintenance

0.69 Upgrades

0.68 Alerts may be inactivated or ignored

0.66 Network and internet access

0.66 History and alerts may not be updated

0.59 Difficult to identify patient's preferred pharmacy

0.56 Users may rely on the system and be less careful

0.53 Customization

0.52 Wrong patient may be selected

0.48 Burdensome regulations for e-prescribing controlled substances

0.45 Vendor may go out of business and/or not support the e-prescribing system

0.39 Adverse impact on interactions with patients

0.37 Information overload

0.36 IT staff

0.33 Hardware

0.29 Changes in role

0.23 Communication problems

0.19 Possible supervision by third parties, including payers

0.16 Potential for new major errors, creating adverse effects on safety

0.13 Might be necessary to redo e-prescription

0.10 Potential for new minor errors, creating inconvenience

0.06 Risk of violation of data security

0.03 entirely dependent on technology

aThe positives and negatives were rank ordered, computed as weighted averages, and converted to proportions. Categories were health, finances, effort, time, management, and data.

${ }^{b}$ The positives and negatives that were added by the respondents in round 1 are shown in italics.

IT = information technology.

usage. Negatives: implementation costs and maintenance costs (Table 3).

Payers and purchasers. Positives: increased efficiency, more readily available data, and increased generic/formulary usage. Negatives: scattered data due to use of multiple different sys- tems, the effort needed to manage a formulary across multiple systems, and implementation costs (Table 4).

Pharmacies, dispensers, and pharmacists. Positives: time, increased efficiency, and fewer medication errors. Negatives: implementation costs and training (Table 5). 


\section{TABLE 3 Key Stakeholders: Pharmacy Benefit Managers and Prescription Pricing Authorities—E-Prescribing} Positives and Negatives ${ }^{\mathrm{a}, \mathrm{b}}$

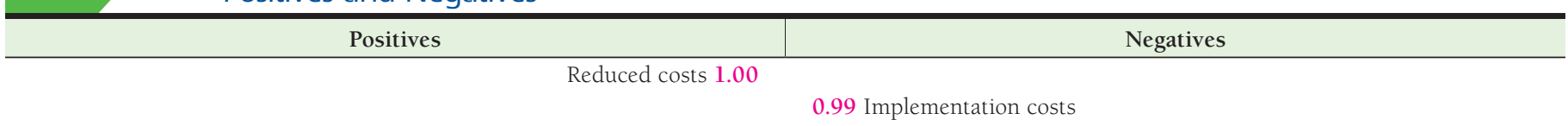

\begin{tabular}{|l|}
\hline Health \\
Finances \\
Effort \\
$\square$ Time \\
Management \\
Data \\
\hline
\end{tabular}

Increased generic/formulary usage 0.88

\subsection{Maintenance}

Increased efficiency 0.76

More readily accessible data 0.72

0.70 Uneven adoption/use by clinicians/prescribers

0.62 Software licensing fees

Improved quality of data $0.58 \quad 0.58$ Upgrades

0.54 IT staff

More data available for analysis 0.48

Could experience increased value or business 0.40

\subsection{Training}

0.45 Use of multiple different e-prescribing system

0.26 Network and internet access

0.25 Potential increase in medication spending

0.19 Customization

Fewer adverse drug events 0.18

0.14 Hardware

Bbetter medication adherence/compliance 0.12 Better marketing facilitation to payers 0.12

aThe positives and negatives were rank ordered, computed as weighted averages, and converted to proportions. Categories were health, finances, effort, time, management, and data.

${ }^{b}$ The positives and negatives that were added by the respondents in round 1 are shown in italics.

IT = information technology.

\section{Other Primary Stakeholders}

Other primary stakeholders were indentified as inpatient and outpatient facilities, employers, and pharmaceutical manufacturers. From the survey rounds, the main positives and negatives of e-prescribing for each of these stakeholders are summarized as follows:

Inpatient and outpatient facilities. Positives: available patient medication history, increased efficiency, and fewer medication errors. Negatives: implementation costs, poor fit with workflow, and training.

Employers. Positives: improved care and/or health outcomes and increased efficiency. Negatives: e-prescribing may result in more costs to providers that could be passed on to employers.

Pharmaceutical manufacturers. Positives: more easily analyzed data, increased sales of branded drugs, and increased sales of generic drugs. Negatives: the potential need to provide data compatible with multiple e-prescribing systems, potential demand for more electronic drug information, and decreased sales of branded drugs.

\section{Secondary Stakeholders}

Secondary stakeholders were identified as patient families, HIT vendors, pharmaceutical suppliers/distributors, consultants, policymakers and legislators, researchers, and society. From the survey rounds, the main positives and negatives of e-prescribing for each of these stakeholders are summarized as follows:

Patient families. Positives: time savings, fewer errors in prescriptions, lower cost options, and improved health care and/ or health outcomes. Negatives: the pharmacy must be chosen when the prescription is made; controlled substances may have to be prescribed on paper; there is a potential for new errors; and it prevents competitive shopping for prescription price.

HIT vendors. Positives: increased in value or business and potential new market for electronic systems or tools for patients. Negatives: the effort of promoting interoperability among health information systems, the effort of integrating new and existing systems, and increased costs.

Pharmaceutical suppliers/distributors. Positives: more readily available data and increased efficiency. Negatives: possible requirement to make systems interoperable with those used by other stakeholders and possible decrease in value or business.

Consultants. Positives: possible increase in value or business and increase in demand for services. Negatives: possible decrease in value or business.

Policymakers and legislators. Positives: better data with which to make decisions, improved patient safety, reduced costs, and increased efficiency. Negatives: costs to other stakeholders. 


\section{TABLE 4 Key Stakeholder: Payers and Purchasers-E-Prescribing Positives and Negatives ${ }^{\mathrm{a}, \mathrm{b}}$}

\begin{tabular}{|c|c|}
\hline Positives & Negatives \\
\hline
\end{tabular}

More readily available data 0.87

0.91 Scattered data due to use of multiple different systems

\begin{tabular}{|l|}
\hline Health \\
Finances \\
Effort \\
Time \\
Management \\
Data \\
\hline
\end{tabular}

Increased generic/formulary usage 0.81

Better oversight of clinician behavior 0.67

Fewer medication errors 0.41

Fewer adverse drug events 0.39

Better medication adherence/compliance 0.30

Improved patient safety 0.30

Improved care and/or health outcomes 0.09
0.86 Effort to manage formulary across multiple systems

0.82 Implementation costs

0.65 Interfaces

0.62 Uneven adoption/use by clinicians/prescribers

0.59 Maintenance

0.39 Upgrades

0.32 Software licensing fees

0.24 Network and internet access

0.17 Vendor may go out of business and/or not support e-prescribing system 0.09 Customization

aThe positives and negatives were rank ordered, computed as weighted averages, and converted to proportions. Categories were health, finances, effort, time, management, and data.

${ }^{b}$ The positives and negatives that were added by the respondents in round 1 are shown in italics.

IT = information technology.

Researchers. Positives: access to better data and more readily available data. Negatives: data scattered on different systems may not be interoperable, and it may be more difficult to obtain complete data because some will be in electronic format and some in paper format.

Society. Positives: increased efficiency, improved care and/or health outcomes, reduced costs, and better oversight of medication usage. Negatives: providers may experience more costs, which may be passed on to society.

\section{Additional Stakeholders}

The survey respondents also identified 3 additional stakeholders: patient associations and support groups, government prescription monitoring programs, and nonclinical staff and health information system providers. Positives and negatives were identified for each of these but were not rank ordered.

\section{E-Prescribing Framework}

Most of the framework experts thought that the e-prescribing framework was useful and/or helpful for payers, integrated delivery systems, policymakers and legislators, and those who influence public policy in the development of incentives and payment mechanisms. The framework experts cited the value of identifying and rank ordering the positives and negatives from the perspectives of the stakeholders, the usefulness of analyzing different informatics technologies, flexibility, and value from a policy perspective.
Generally, patients were cited as the most important stakeholders, followed by clinicians and then pharmacists. The framework experts did not believe that the results of this study were different than what they would have expected in an inpatient e-prescribing system, except for perhaps the large number of negatives from the clinician perspective.

\section{Return on Investment}

The framework experts agreed that all stakeholders and all positives and negatives should be considered in developing an ROI; 1 framework expert suggested that the ROI would be best for pharmacies. This same framework expert suggested that the benefit of e-prescribing and certain other health information technologies inures primarily to society and the overall health care system. Some of the framework experts believed that it is important to expand the considerations in determining an ROI, such as considering the value of better health, population management, better productivity, greater safety, better quality, and better health outcomes. All the framework experts believed that the framework is generalizable to other health information technologies, depending on the nature of those technologies. This observation can be a key to how pharmacists in their new roles on care teams address incentives from the perspective of the various stakeholders. 
TABLE 5 Key Stakeholders: Pharmacies, Dispensers, and Pharmacists-E-Prescribing Positives and Negatives ${ }^{\mathrm{a}, \mathrm{b}}$

\begin{tabular}{l}
\hline Health \\
\hline Hinances \\
Effort \\
Time \\
Management \\
Mata \\
\hline Data
\end{tabular}

Better ability to monitor adherence/compliance 0.58

Fewer fraudulent prescriptions 0.48

Improved patient satisfaction 0.44

Improved communication 0.38

Faster information transfer 0.33

More time for consultations 0.28

Improved care and/or health outcomes 0.24

Increased business for prescriptions and other purchases 0.21

\subsection{Implementation costs}

Negatives

0.89 Training

0.73 Software licensing fees

0.64 Maintenance

0.55 Upgrades

0.44 Network and internet access

0.40 Time consuming

0.35 Changes in role

0.35 Potential adverse effect on safety

0.31 Hardware

0.20 Potential adverse effect on relationship with patient

Increased generic/formulary usage 0.07

\footnotetext{
aThe positives and negatives were rank ordered, computed as weighted averages, and converted to proportions. Categories were health, finances, effort, time, management, and data.

${ }^{b}$ The positives and negatives that were added by the respondents in round 1 are shown in italics.
}

\section{Summarizing Consensus}

Appendix B (available in online article) presents a high-level overview summarizing the experts' consensus regarding the relative effect of the many positive and negative attributes of e-prescribing on the various stakeholders. Six broad categories of stakeholders were identified (see Appendix B), and 6 broad categories of positive and negative attributes were identified: data, effort, finance, health, management, and time. By totaling the weighted averages of attributes within these categories, it is possible to represent the overall effects of e-prescribing on the entire health care system.

\section{Discussion}

This study attempts to identify all of the stakeholders involved in e-prescribing and all of the corresponding positives and negatives from the perspective of each stakeholder. The costs of e-prescribing systems can vary dramatically, and an attempt to quantify the costs may be less helpful than rank ordering the positives and negatives from the perspective of each stakeholder. From the survey questions, a framework was created that can be used by payers, policymakers and legislators, and those who influence public policy, particularly in the transition from systems based on fee for service to those based on quality and cost-effectiveness.

Most of the previous research assumes a fee-for-service system, which is increasingly less relevant as the U.S. health care system moves to pay for quality and performance in a cost-effective manner. In pursuit of an ROI analysis, most previous research does not recognize the need for physicians to have access to clinical information in order to manage care in a patient-centered medical home model or to function in a world of population health management and value-based payment.

The framework experts believed that the e-prescribing framework resulting from the survey research was useful and could be successfully used by payers, integrated delivery systems, policymakers and legislators, and those who influence public policy in the development of incentives and payment mechanisms. The framework can help define the key role that pharmacists will play in care teams facilitated by HIT. 
Work based on this study might consider the following questions: Can this e-prescribing research be applied to other health information technologies? Will the rank ordering done in this study accurately represent the order determined by individual stakeholders in an individual market? How should pharmacists in their new role in care teams implement HIT to facilitate care management in the context of the existing stakeholders?

Research efforts could address the quantification of the positives and negatives where possible in the context of a system, perhaps with a focus on research for a systemwide ROI. In addition, research might also address the measurement of the value of harm reduction, reduced length of stay, mortality, and readmission rates.

\section{Limitations}

This Delphi study, as is typical of such studies, did not provide statistically significant results. The initial list of stakeholders and positives and negatives were determined by the study authors through a literature search. Although much agreement was achieved, as indicated by the high weighted averages for some positives and negatives associated with e-prescribing, the ideas generated through this study were summary measures.

Although a seemingly limited number of experts were involved, they represent a significant proportion of the leading experts in the field. The research followed established, validated methods previously used in Delphi studies designed to address health information technology questions.

\section{Conclusions}

The positives and negatives associated with HIT, such as e-prescribing, do not appear to be well understood. It is possible to use the Delphi method to identify stakeholders and the positives and negatives of e-prescribing from the perspective of each stakeholder. Experts can rank order the positives and negatives from the perspective of each stakeholder, and the category of stakeholder can be identified.

Disparate framework experts found the framework generalizable to HIT and useful for use by payers, integrated delivery systems, and those who influence public policy in the development of incentives and payment mechanisms. They also found it to be comprehensive and primarily focused on the importance of the patients and clinicians. They were not surprised by the findings and recognized the importance of incentives but had differing views on them. The framework experts noted that it is not possible to fully participate in today's payment for quality and cost-effectiveness models without access to HIT, such as e-prescribing, and that any ROI calculations should include all applicable stakeholders and the positives and negatives.

\section{Authors}

PAUL R. DEMURO, PhD, JD, MBA, Broad and Cassel, Attorneys at Law, Fort Lauderdale, Florida. JOAN ASH, PhD, MLS, MBA, and JUSTIN FLETCHER, MBI, PhD, Oregon Health E Science University School of Medicine, Portland, Oregon. BLACKFORD MIDDLETON, MD, MPH, MSc, Apervita, Chicago, Illinois, and Harvard T.H. Chan School of Public Health, Health Policy and Management, Boston, Massachusetts. CECELIA J. MADISON, MBI, Oregon Health E Science University School of Medicine, Portland, Oregon, and California State University School of Nursing, Chico.

AUTHOR CORRESPONDENCE: Paul R. DeMuro, PhD, JD, MBA, Broad and Cassel, One Financial Plaza, Ste. 2700, Fort Lauderdale, FL 33394. Tel.: 213.308.7859; E-mail: pdemuro@broadandcassel.com.

\section{DISCLOSURES}

This research was supported by the National Library of Medicine of the National Institutes of Health under Award Number T15LM007088. The authors declare no conflicts of interest in the research.

Study concept and design were contributed by DeMuro, Ash, Middleton, and Fletcher. DeMuro took the lead in data collection, along with Ash, and data interpretation was performed by DeMuro, Ash, Madison, Middleton, and Fletcher. The manuscript was written primarily by DeMuro, along with Ash and Middleton, and revised by DeMuro, Madison, and Ash, along with Middleton and Fletcher.

\section{REFERENCES}

1. Cooke CE, Isetts BJ, Sullivan TE, Fustgaard M, Belletti DA. Potential value of electronic prescribing in health economic and outcomes research. Patient Relat Outcome Meas. 2010;1:163-78.

2. Dhavie AA, Ward-Charlerie S, Rupp MT, Amin VP, Ruiz, J. Analysis of National Drug Code identifiers in ambulatory e-prescribing. J Manag Care Spec Pharm. 2015;21(11):1025-31. Available at: http://www.jmcp.org/ doi/10.18553/jmcp.2015.21.11.1025.

3. Andrus MR, Forrester JG, Germain KE, Eiland LS. Accuracy of pharmacy benefit manager medication formularies in an electronic health record system and the Epocrates mobile application. J Manag Care Spec Pharm. 2015;21(4);281-86. Available at: http://www.jmcp.org/doi/10.18553/ jmcp.2015.21.4.281.

4. Poon EG, Jha AK, Christine M, et al. Assessing the level of healthcare information technology adoption in the United States: a snapshot. BMC Med Inform Decis Mak. 2006;6:1.

5. Schade CP, Sullivan FM, de Lusignan S, Madeley J. e-Prescribing, efficiency, quality: lessons from the computerization of UK family practice. J Am Med Inform Assoc. 2006;13(5):470-75.

6. Adler-Milstein J, Gregory D, Grossmann C, et al. Return on information a standard model for assessing institutional return on electronic health records. Discussion paper. Institute of Medicine. January 6, 2014. Available at: https://nam.edu/wp-content/uploads/2015/06/ReturnonInformationl. pdf. Accessed September 17, 2017.

7. Balfour DC, Evans S, Januska J, et al. Health information technologyresults from a roundtable discussion. J Manag Care Pharm. 2009;15

(1 Suppl A):S10-S17. Available at: http://www.jmcp.org/doi/abs/10.18553/ jmcp.2009.15.sl.10. 
8. Ross SM, Papshev D, Murphy EL, Sternberg DJ, Taylor J, Barg R. Effects of electronic prescribing on formulary compliance and generic drug utilization in the ambulatory care setting: a retrospective analysis of administrative claims data. J Manag Care Pharm. 2005;11(5):410-15. Available at: http:// www.jmcp.org/doi/10.18553/jmcp.2005.11.5.410.

9. Leung MY, Halpern MT, West ND. Pharmaceutical technology assessment: perspective from payers. J Manag Care Pharm. 2012;18(3):256-64. Available at: http://www.jmcp.org/doi/10.18553/jmcp.2012.18.3.256.

10. Wang SJ, Middleton B, Prosser LA, et al. A cost-benefit analysis of electronic medical records in primary care. Am J Med. 2003;114(5):397-403.

11. Fischer MA, Vogeli C, Stedman M, Ferris T, Brookhart, MA, Weissman JS. Effect of electronic prescribing with formulary decision support on medication use and cost. Arch Intern Med. 2008;168(22):2433-39.

12. McMullin ST. Standardization is necessary in the methods to assess the value of electronic accessing systems. J Manag Care Pharm. 2005;11(7):594-95. Available at: http://www.jmcp.org/doi/10.18553/jmcp.2005.11.7.594.

13. Shah S, Kaelber DC, Vincent A, Pan EC, Johnston D, Middleton B. A cost model for personal health records (PHRs). AMIA Annu Symp Proc. 2008:657-61.

14. Johnston D, Kaelber D, Pan EC, et al. A framework and approach for assessing the value of personal health records (PHRs). AMIA Annu Symp Proc. 2007:374-78

15. Byrne CM, Mercincavage LM, Pan EC, Vincent AG, Johnston DS, Middleton B. The value from investments in health information technology at the U.S. Department of Veteran Affairs. Health Aff (Millwood). 2010;29(4):629-38.

16. Cusack CM, Pan E, Hook JM, Vincent A, Kaelber DC, Middleton B. The value proposition in the widespread use of telehealth. J Telemed Telecare. 2008;14:167-68.

17. Kaushal R, Jha AK, Franz C, et al. Return on investment for a computerized physician order entry system. J Am Med Inform Assoc. 2006;13:261-66.

18. Pan E, Cusack CM, Hook JM, Middleton B. Cost of interconnecting health information exchange to form a national network. AMIA Annu Symp Proc. 2007:583-87.
19. Walker J, Pan E, Johnston D, Adler-Milstein J, Bates DW, Middleton B. The value of health care information exchange and interoperability. Health Aff (Millwood). 2005;19:w5-10.

20. Sprivulis P, Walker J, Johnston D, et al. The economic benefits of health information exchange interoperability for Australia. Aust Health Rev. 2007;31(4):531-39.

21. Kaushal R, Blumenthal D, Poon EG, et al. The costs of a national health information network. Ann Intern Med. 2005;143(3):165-73.

22. Miller RH, West C, Brown TM, Sim I, Gonchoff C. The value of electronic health records in solo or small group practices. Health Aff (Millwood). 2005;24(5):1127-37.

23. Halamka J, Aranow M, Ascenzo C, et al. E-prescribing collaboration in Massachusetts: early experiences from regional prescribing projects. J Am Med Inform Assoc. 2006;13(3):239-44.

24. Hillblom D, Schueth A, Robertson SM, Topor L, Low G. The impact of information technology on managed care pharmacy: today and tomorrow. J Manag Care Spec Pharm. 2014;20(11):1073-79. Available at: http://www. jmcp.org/doi/10.18553/jmcp.2014.20.11.1073.

25. Sittig DF, Wright A, Ash JS, Middleton B. A set of preliminary standards recommended for achieving a national repository of clinical decision support interventions. AMIA Annu Symp Proc. 2009:614-18.

26. Dalkey N, Helmer O. An experimental application of the Delphi method to the use of experts. Manag Sci. 1963;9(3):458-67.

27. Dalkey NC. The Delphi method: an experimental study of group opinion. The RAND Corporation. June 1969. Available at: https://www.rand.org/pubs/ research_memoranda/RM5888.readonline.html. Accessed September 17, 2017.

28. Okoli C, Pawlowski SD. The Delphi method as a research tool: an example, design considerations and applications. Information \& Management. 2004:42(1):15-29.

29. Cusack CM. Electronic health records and electronic prescribing: promises and pitfalls. Obstet Gynecol Clin North Am. 2008;35(1):63-79. 


\section{APPENDIX A Framework Experts Description and Questions}

The framework experts chosen for this study are described below:

1. An expert in accountable care organizations and in-house counsel at a major teaching hospital, who works extensively with new integrated delivery models and physicians.

2. The CEO of a major regional health plan, which is extensively involved with managed care, pharmacy benefit managers, physicians, and pharmacists.

3. A senior analyst with the Department of Health and Human Services Office of the National Coordinator, a U.S. government entity that focuses on health information technology, such as e-prescribing and its adoption, implementation, use, and interoperability.

4. The senior vice president, chief financial officer, and treasurer of a major clinically integrated health care system that includes many hospitals and employed and contracted physicians and pharmacists.

5. An expert in e-prescribing with the National Health Service in the United Kingdom, who is a pharmacist.

Questions asked of the framework experts:

1. What aspects of the framework do you find most useful?

2. Which stakeholders do you view as particularly important?

3. Please identify any stakeholders that are not identified that you think would be important to include. Why?

4. Please identify any of the stakeholders included that you think would be of much less significance. Why?

5. Are there any important positives or negatives for a particular stakeholder that you think were missed? If so, what are they?

6. If the results of the Delphi study differed substantially from what you would have expected, in what way do the results differ?

7. What incentives for the use of e-prescribing for the stakeholders, financial or otherwise, might you view as particularly important?

8. Would you like to comment on the potential value and extent of any such incentives?

9. Are there any particular barriers to the implementation of stakeholder incentives that you would like to identify?

10. How would you characterize the return on investment, given the positives and negatives accruing to multiple stakeholders, and not merely 1 stakeholder?

11. This study has used e-prescribing as an example of a health information technology. What is your opinion about how generalizable this framework might be to other health information technologies? 
APPENDIX B Overview of Stakeholder Categories and Positive/Negative Attributes

The following is a summary of the stakeholder categories for those primarily in the business of e-prescribing, those involved in the business of e-prescriptions (pharmaceutical manufacturers, vendors of health information technology, pharmacy benefit managers/prescription pricing authorities, suppliers/ distributors of pharmaceuticals, and consultants); those paying for e-prescriptions (payers/purchasers and employers); those providing e-prescriptions (clinicians/ prescribers, health care entities, pharmacies/dispensaries, and nonclinical health care staff); those receiving e-prescriptions (patients, patient families, society, and support groups); those involved in regulating e-prescriptions (policymakers and legislators); and those studying e-prescriptions (researchers and the government), along with the attributes of data, effort, finances, health, management, and time.

Positive attributes are shown in green and in the left column under each stakeholder, while negative attributes are shown in red and in the right column. The size of the type indicates the relative size of each attribute's effect. It was assumed that neither the legislative nor corporate policymakers for whom the framework was designed would devote extensive time to studying the effects of e-prescribing at the granularity presented in this study; thus, this chart offers an opportunity to quickly assess the distribution of the benefits and burdens of e-prescribing.

Stakeholders involved in

paying for e-prescriptions

\section{Health Effort}

Stakeholders involved in the
business of e-prescriptions

